\title{
EFEK WAKTU PASAR DAN KEBIJAKAN INVESTASI TERHADAP STRUKTUR MODAL
}

\author{
Winston Pontoh \\ (Email : winston_pontoh@yahoo.com)
}

\begin{abstract}
The capital structure policy by an entity is still a question specially in the context of investment policy and if related to market timing. The question is still exist because the entity faced by two options of financing which are internal financing (capital) and external financing (debt).

This study is using data from the samples of 241 entities listed in Indonesia Stock Exchange in period of 2009 till 2012 making the total of observed data are 964.

Conducting multiple regression analysis, this study conclude that, the effect of pecking order, trade off and market timing are not absolute for all conditions of entities, because the entities will take decision for capital structure policy based on its conditions such as internally or externally. In this case, the external condition is referring to capital market.

Keywords : pecking order, trade off, market timing
\end{abstract}

\section{Pendahuluan}

Kebijakan struktur modal dari sebuah entitas bisnis masih menjadi sebuah permasalahan khususnya dalam konteks kebijakan investasi dan jika dikaitkan dengan efek waktu pasar. Permasalahan ini disebabkan karena entitas bisnis masih diperhadapkan dengan 2 (dua) pilihan pembiayaan yaitu yang berasal dari modal sendiri atau menggunakan dana eksternal berupa modal utang. Dalam sudut pandang pihak eksternal entitas, dasar pertimbangan untuk penetapan struktur modal entitas masih sulit dipahami karena entitas bisnis dipandang sebagai sebuah "kotak hitam" (Zingales, 2000). Selain dukungan teori pecking order dan trade off (Cheng dan Shiu, 2007), di pihak lain, Marsh (1982) dan Masulis (1983) menyatakan bahwa, pemilihan struktur modal sebuah entitas bisnis lebih banyak dipengaruhi oleh harga pasar saham yang merupakan bentuk dari efek waktu pasar.

Penelitian ini melanjutkan hasil penelitian dari Pontoh (2014) dan bertujuan untuk memberikan bukti empiris tentang dasar pertimbangan penetapan struktur modal sebuah entitas bisnis dalam konteks kebijakan investasi, berdasarkan teori pecking order, trade off dan waktu pasar (market timing).

\section{Tinjauan Pustaka}

Teori struktur modal adalah teori yang digunakan untuk menjelaskan berbagai kombinasi surat-surat berharga dan sumber pendanaan yang digunakan oleh sebuah entitas bisnis dalam membiayai kegiatan investasinya (Myers, 2001; Chemmanur, Nandy, Yan, dan Jiao, 2014; Acharya, Almeida, dan Campello, 2007), dan beberapa teori kondisional yang sering diaplikasikan adalah Trade Off Theory dan Pecking Order Theory (Sunder dan Myers, 1999; Myers, 2001).

Fama dan French (2002) menjelaskan bahwa, dalam model trade off, adanya biaya keagenan, pajak dan biaya kebangkrutan akan mendorong entitas bisnis yang memiliki profitabilitas yang tinggi untuk menggunakan utang dalam jumlah yang tinggi. Sedangkan dalam model pecking order, semakin tinggi laba yang diperoleh entitas bisnis akan mengakibatkan berkurangnya penggunaan utang.

Kayhan dan Titman (2007) yang menemukan bahwa, harga saham memiliki pengaruh negatif signifikan terhadap rasio utang (yang diukur dengan rasio total utang atas total aset), dalam arti bahwa, entitas bisnis akan cenderung menerbitkan saham baru pada saat harga 
pasar saham mengalami kenaikan. Baker dan Wurgler (2002) menyebutnya sebagai efek waktu pasar (market timing)

Graham (1996) menemukan bahwa, kepemilikan aset tetap memiliki pengaruh positif signifikan terhadap rasio utang (yang diukur dengan perubahan rasio utang atas ekuitas). Crutchley, Jensen, Jahera, dan Raymond (1999) menemukan bahwa, kepemilikan aset tetap memiliki pengaruh positif signifikan terhadap rasio utang (yang diukur dengan rasio utang jangka panjang atas total aset). Frank dan Goyal (2003) menemukan bahwa, kepemilikan aset tetap dari entitas bisnis memiliki pengaruh positif signifikan terhadap rasio utang (yang diukur dengan rasio utang atas aset).

\section{Hipotesis dan Model}

Fama dan French (2002) menjelaskan bahwa, dalam model trade off, adanya biaya keagenan, pajak dan biaya kebangkrutan akan mendorong entitas bisnis yang memiliki profitabilitas yang tinggi untuk menggunakan utang dalam jumlah yang tinggi. Sedangkan dalam model pecking order, semakin tinggi laba yang diperoleh entitas bisnis akan mengakibatkan berkurangnya penggunaan utang. Pendapat ini didukung oleh hasil penelitian dari Byoun (2008) yang menemukan bahwa, profitabilitas memiliki pengaruh signifikan terhadap rasio utang. Hasil penelitian ini juga didukung oleh Jensen, Solberg, dan Zorn (1992) dan Lucey dan Zhang (2011).

\section{$\mathrm{Ha}_{1}$ : Profitabilitas memiliki pengaruh signifikan terhadap rasio utang.}

Hovakimian, Opler, dan Titman (2001) menjelaskan bahwa, harga pasar saham sebuah entitas bisnis dapat mempengaruhi pemilihan struktur modal entitas bisnis tersebut. Jika harga pasar saham sebuah entitas bisnis berada posisi yang rendah dari posisi pengembalian atau nilai bukunya, maka para manajer dari pihak internal cenderung untuk tidak menerbitkan saham tambahan. Hasil penelitian ini didukung oleh Warr, Elliott, Kant, dan Öztekin (2012) dan Bonaimé, Öztekin, dan Warr (2014).

\section{$\mathrm{Ha}_{2}$ : Harga pasar saham memiliki pengaruh signifikan terhadap rasio utang.}

Whited (1992) menjelaskan bahwa, sebuah entitas bisnis yang berukuran lebih kecil dengan likuiditas aset yang lebih rendah akan memiliki kesulitan untuk memperoleh fasilitas pendanaan karena aset yang dimiliki tidak mencukupi untuk digunakan sebagai jaminan utang. Pendapat ini didukung oleh Jensen, Solberg, dan Zorn (1992) dan Crutchley, Jensen, Jahera, dan Raymond (1999) yang menemukan bahwa, kepemilikan aset tetap memiliki pengaruh signifikan terhadap rasio utang.

\section{$\mathrm{Ha}_{3}$ : Kepemilikan aset tetap memiliki pengaruh signifikan terhadap rasio utang.}

Berdasarkan rumusan hipotesis, maka model persamaan dalam penelitian ini dapat dirumuskan berdasarkan beberapa kondisi sebagai berikut :

$\mathrm{DAR}=\alpha+\beta \mathrm{ROA}+\beta$ Price $+\beta$ Tang

$\mathrm{DAR}_{<\text {med }}=\alpha+\beta \mathrm{ROA}_{<\text {med }}+\beta$ Price $+\beta$ Tang $_{<\text {med }}$

$\mathrm{DAR}_{<\text {med }}=\alpha+\beta \mathrm{ROA}_{>\text {med }}+\beta$ Price $+\beta$ Tang $_{>\text {med }}$

$\mathrm{DAR}_{<\mathrm{med}}=\alpha+\beta \mathrm{ROA}_{<\mathrm{med}}+\beta$ Price $+\beta$ Tang $_{>\text {med }}$

$\mathrm{DAR}_{<\text {med }}=\alpha+\beta \mathrm{ROA}_{>\text {med }}+\beta$ Price $+\beta$ Tang $_{<\text {med }}$

$\mathrm{DAR}_{>\text {med }}=\alpha+\beta \mathrm{ROA}_{<\mathrm{med}}+\beta$ Price $+\beta$ Tang $_{<\mathrm{med}}$

$\mathrm{DAR}_{>\text {med }}=\alpha+\beta \mathrm{ROA}_{>\text {med }}+\beta$ Price $+\beta$ Tang $_{>\text {med }}$

$\mathrm{DAR}_{>\text {med }}=\alpha+\beta \mathrm{ROA}_{<\mathrm{med}}+\beta$ Price $+\beta$ Tang $_{>\text {med }}$

$\mathrm{DAR}_{>\text {med }}=\alpha+\beta \mathrm{ROA}_{>\text {med }}+\beta$ Price $+\beta$ Tang $_{<\text {med }}$ 


\section{Metode Penelitian}

\subsection{Data}

Data dalam penelitian ini mengambil sampel 241 entitas bisnis yang terdaftar dalam Bursa Efek Indonesia pada periode tahun 2009 sampai dengan tahun 2012. Data observasi dalam penelitian ini secara keseluruhan adalah berjumlah 964 data observasi.

\subsection{Variabel dan Pengukuran Variabel}

Variabel-variabel yang digunakan dalam penelitian ini adalah sebagai berikut :

1. Rasio utang.

Rasio utang digunakan sebagai variabel dependen yang diproksikan dengan rasio total utang atas total aset (selanjutnya disingkat dengan DAR) dan diukur dengan persen. Variabel ini mengontrol nilai tengah (median) dari rata-rata rasio utang selama 4 tahun, sehingga entitas dengan nilai DAR yang berada dibawah nilai tengah akan dianalogikan sebagai entitas yang memiliki rasio utang yang rendah dan begitu juga sebaliknya.

2. Profitabilitas.

Profitabilitas digunakan sebagai variabel independen yang diukur dengan rasio laba bersih atas total aset (selanjutnya disingkat ROA) dan diukur dengan persen. Variabel ini mengontrol nilai tengah (median) dari rata-rata rasio laba bersih atas total aset selama 4 tahun, sehingga entitas dengan nilai ROA yang berada dibawah nilai tengah akan dianalogikan sebagai entitas dengan profitabilitas rendah dan begitu juga sebaliknya.

3. Harga pasar saham.

Harga pasar saham digunakan sebagai variabel independen yang mengambil harga pasar saham penutupan setelah disesuaikan dengan kebijakan entitas (adjusted closing price) dan dinormalisasi dengan menggunakan logaritma natural (selanjutnya disingkat Price).

4. Kepemilikan aset tetap.

Kepemilikan aset tetap digunakan sebagai variabel independen yang diproksikan dengan rasio aset tetap atas total aset (selanjutnya disingkat Tang) dan diukur dengan persen. Variabel ini dikontrol berdasarkan nilai tengah (median) atas rata-rata rasio aset tetap atas total aset selama 4 tahun, sehingga entitas dengan nilai Tang yang berada dibawah nilai tengah akan dianalogikan sebagai entitas yang memiliki nilai aset tetap yang rendah dan begitu juga sebaliknya.

\subsection{Metode Analisis}

Dalam penelitian ini, metode analisis yang akan digunakan untuk pengujian hipotesis adalah menggunakan uji regresi berganda yang digunakan berdasarkan data panel.

\section{Hasil Analisis dan Pembahasan}

\subsection{Hasil Analisis}

Statistik deskriptif menunjukkan hasil sebagai berikut :

Tabel 1. Statistik Deskriptif

\begin{tabular}{|c|c|}
\hline Keterangan & Nilai Tengah (Median) \\
\hline DAR & 0.51 \\
\hline ROA & 0.05 \\
\hline Tang & 0.34 \\
\hline
\end{tabular}

Berdasarkan nilai tengah dalam analisis statistik deskriptif (lihat Tabel 1), maka kontrol atas variabel DAR, ROA dan Tang dapat dilakukan berdasarkan nilai tengah tersebut. 
Tabel 2. Analisis Regresi Berganda

\begin{tabular}{|c|c|c|c|c|c|c|c|c|c|}
\hline & \multirow{2}{*}{$\begin{array}{c}\text { DAR } \\
(1)\end{array}$} & \multicolumn{4}{|c|}{$\mathrm{DAR}_{<\mathrm{med}}$} & \multicolumn{4}{|c|}{$\mathrm{DAR}_{>\text {med }}$} \\
\hline & & (2) & (3) & (4) & (5) & (6) & $(7)$ & (8) & $(9)$ \\
\hline Konstan & 0.866 & 0.269 & 0.600 & 0.195 & 0.240 & 0.858 & 1.456 & 0.814 & 1.381 \\
\hline ROA & $-0.262 *$ & & & & & & & & \\
\hline $\mathrm{ROA}_{<\mathrm{med}}$ & & -0.032 & & -0.087 & & $-1.176^{*}$ & & $-2.312 *$ & \\
\hline $\mathrm{ROA}_{>\text {med }}$ & & & -0.006 & & -0.163 & & 0.306 & & $0.924 *$ \\
\hline Price & $-0.040 *$ & 0.003 & $-0.042 *$ & 0.029 & 0.002 & 0.000 & $-0.089 *$ & 0.059 & -0.070 \\
\hline Tang & -0.044 & & & & & & & & \\
\hline Tang $_{<\text {med }}$ & & 0.197 & & & $0.444^{*}$ & -0.408 & & & -0.819 \\
\hline Tang $_{>\text {med }}$ & & & $0.133^{*}$ & -0.004 & & & -0.109 & $-0.803 *$ & \\
\hline
\end{tabular}

*signifikan pada tingkat 5\%

Berdasarkan hasil analisis regresi (lihat Tabel 2), ditemukan bahwa profitabilitas (ROA) dalam kondisi 1, kondisi 6 , kondisi 8 dan kondisi 9 memiliki pengaruh signifikan terhadap rasio utang (DAR), dimana hasil ini sesuai dengan hasil penelitian dari Byoun (2008), Jensen, Solberg, dan Zorn (1992) dan Lucey dan Zhang (2011). Demikian juga dengan harga pasar saham (Price), dalam kondisi 1, kondisi 3, dan kondisi 7 memiliki pengaruh signifikan terhadap rasio utang (DAR), dimana hasil ini sesuai dengan hasil penelitian dari Hovakimian, Opler, dan Titman (2001), Warr, Elliott, Kant, dan Öztekin (2012) dan Bonaimé, Öztekin, dan Warr (2014). Sedangkan kepemilikan aset tetap (Tang), dalam kondisi 3, kondisi 5, dan kondisi 8 memiliki pengaruh signifikan terhadap rasio utang (DAR), dimana hasil ini sesuai dengan hasil penelitian dari Jensen, Solberg, dan Zorn (1992) dan Crutchley, Jensen, Jahera, dan Raymond (1999).

\subsection{Pembahasan}

Kondisi 1 menunjukkan adanya efek pecking order dimana semakin tinggi profitabilitas dan kepemilikan aset tetap, maka rasio utang dari entitas akan mengalami penurunan, walaupun kepemilikan aset tetap tidak signifikan. Selain itu, efek waktu pasar (market timing) juga berlaku dalam kondisi ini, dimana pada saat kenaikan harga pasar saham, maka entitas bisnis cenderung untuk menurunkan rasio utangnya. Akan tetapi kondisi 1 bukan merupakan kondisi mutlak, karena pada saat dilakukan kontrol atas variabel rasio utang, profitabilitas dan kepemilikan aset tetap, efek dari pecking order tidak terjadi, melainkan trade off, seperti yang ditunjukkan dalam kondisi 7 dan kondisi 9, walaupun kondisi 7 menunjukkan pengaruh tidak signifikan dari profitabilitas terhadap rasio utang.

Tanpa memandang signifikansi, secara khusus dapat dinyatakan bahwa, dalam kondisi 2, entitas bisnis dengan kondisi memiliki rasio utang yang rendah, profitabilitas yang rendah dan kepemilikan aset tetap yang rendah cenderung menurunkan rasio utangnya pada saat terjadi peningkatan atas profitabilitas dan cenderung meningkatkan rasio utangnya pada terjadi peningkatan dalam kepemilikan aset tetap (terjadi investasi tambahan) dan pada saat harga pasar saham meningkat. Dalam kondisi 3, entitas bisnis dengan kondisi memiliki rasio utang yang rendah, profitabilitas dan kepemilikan aset tetap yang tinggi cenderung menurunkan rasio utangnya pada saat profitabilitas dan harga pasar saham mengalami peningkatan dan cenderung meningkatkan rasio utang pada saat kepemilikan aset tetap mengalami peningkatan. Dalam kondisi 4, entitas bisnis dengan kondisi memiliki rasio utang yang rendah, profitabilitas yang rendah dan kepemilikan aset tetap yang tinggi cenderung menurunkan rasio utang pada saat profitabilitas dan kepemilikan aset tetap mengalami peningkatan tapi akan cenderung meningkatkan rasio utang pada saat harga pasar saham mengalami peningkatan. Dalam kondisi 5, entitas bisnis dengan kondisi memiliki rasio utang yang rendah, profitabilitas yang tinggi, dan kepemilikan aset tetap yang rendah cenderung menurunkan rasio utang pada saat profitabilitas mengalami peningkatan dan cenderung meningkatkan rasio utang pada saat kepemilikan aset tetap dan harga pasar saham mengalami 
peningkatan. Dalam kondisi 6, entitas bisnis dengan kondisi memiliki rasio utang yang tinggi, profitabilitas yang rendah, dan kepemilikan aset tetap yang rendah cenderung mengurangi rasio utang pada saat profitabilitas dan kepemilikan aset mengalami peningkatan dan cenderung meningkatkan rasio utang pada saat harga pasar saham mengalami peningkatan. Dalam kondisi 7, entitas bisnis dengan kondisi memiliki rasio utang dan profitabilitas serta kepemilikan aset tetap yang tinggi cenderung meningkatkan rasio utangnya pada saat profitabilitas mengalami peningkatan dan cenderung mengurangi rasio utang pada saat kepemilikan aset tetap dan harga pasar saham mengalami peningkatan. Dalam kondisi 8, entitas bisnis dengan kondisi memiliki rasio utang yang tinggi, profitabilitas yang rendah, dan kepemilikan aset tetap yang tinggi cenderung mengurangi rasio utang pada saat profitabilitas dan kepemilikan aset tetap mengalami peningkatan dan cenderung meningkatkan rasio utang pada saat terjadi peningkatan harga pasar saham. Sedangkan dalam kondisi 9, entitas bisnis dengan kondisi memiliki rasio utang dan profitabilitas yang tinggi, serta kepemilikan aset tetap yang rendah cenderung akan meningkatkan rasio utang pada saat profitabilitas mengalami peningkatan dan cenderung mengurangi rasio utang pada saat terjadi peningkatan pada kepemilikan aset tetap dan harga pasar saham.

\section{Kesimpulan}

Efek dari pecking order dan trade off serta market timing tidak mutlak terjadi dalam semua kondisi dari sebuah entitas bisnis, karena entitas bisnis akan mengambil keputusan atas kebijakan struktur modal berdasarkan kondisi-kondisi tertentu dari segi internal entitas bisnis dan berdasarkan pengaruh eksternal entitas yaitu pasar modal.

\section{Daftar Pustaka}

Acharya, V. V., Almeida, H., dan Campello, M. (2007). Is Cash Negative Debt? A Hedging Perspective on Corporate Financial Policies. Journal of Financial Intermediation, 16(4), $515-554$.

Baker, M., dan Wurgler, J. (2002). Market Timing and Capital Structure. The Journal of Finance, 57(1), 1-32.

Bonaimé, A. A., Öztekin, Ö., dan Warr, R. S. (2014). Capital Structure, Equity Mispricing, and Stock Repurchases. Journal of Corporate Finance, 26, 182-200.

Byoun, S. (2008). How and When Do Firms Adjust Their Capital Structures toward Targets? The Journal of Finance, 63(6), 3069-3096.

Chemmanur, T. J., Nandy, D., Yan, A., dan Jiao, J. (2014). A Theory of Mandatory Convertibles. Journal of Banking and Finance, 42, 352-370.

Cheng, S. R., dan Shiu, C. Y. (2007). Investor Protection and Capital Structure : International Evidence. Journal of Multinational Financial Management, 17(1), 30-44.

Crutchley, C. E., Jensen, M. R.H., Jahera, J. S., Jr., dan Raymond, J. E. (1999). Agency Problems and the Simultaneity of Financial Decision Making-The Role of Institutional Ownership. International Review of Financial Analysis, 8(2), 177-197.

Fama, E. F., dan French, K. R. (2002). Testing Trade-Off and Pecking Order Predictions about Dividends and Debt. The Review of Financial Studies, 15(1), 1-33.

Frank, M. Z., dan Goyal, V. K. (2003). Testing the Pecking Order Theory of Capital Structure. Journal of Financial Economics, 67(2), 217-248.

Graham, J. R. (1996). Debt and the Marginal Tax Rate. Journal of Financial Economics, 41(1), 41-73.

Hovakimian, A., Opler, T., dan Titman, S. (2001). The Debt-Equity Choice. The Journal of Financial and Quantitative Analysis, 36(1), 1-24. 
Jensen, G. R., Solberg, D. P., dan Zorn, T. S. (1992). Simultaneous Determination of Insider Ownership, Debt, and Dividend Policies. Journal of Financial and Quantitative Analysis, 27(2), 247-263.

Kayhan, A., dan Titman, S. (2007). Firms' Histories and their Capital Structures. Journal of Financial Economics, 83(1), 1-32.

Lucey, B. M., dan Zhang, Q. Y. (2011). Financial Integration and Emerging Markets Capital Structure. Journal of Banking \& Finance, 35(5), 1228-1238.

Marsh, P. (1982). The Choice Between Equity and Debt : An Empirical Study. The Journal of Finance, 37(1), 121-144.

Masulis, R. W. (1983). The Impact of Capital Structure Change on Firm Value : Some Estimates. The Journal of Finance, 38(1), 107-126.

Myers, S. C. (2001). Capital Structure. The Journal of Economic Perspectives, 15(2), 81-102.

Pontoh, W. (2014). Kebijakan Struktur Modal dan Efek Waktu Pasar. Jurnal Riset Akuntansi Going Concern, 9(3), 1-6.

Sunder, L. S., dan Myers, S. C. (1999). Testing Static Tradeoff against Pecking Order Models of Capital Structure. Journal of Financial Economics, 51(2), 219-244.

Warr, R. S., Elliott, W. B., Kant, J. K. dan Öztekin, Ö. (2012). Equity Mispricing and Leverage Adjustment Costs. Journal of Financial and Quantitative Analysis, 47(3), 589616.

Whited, T. M. (1992). Debt, Liquidity Constraints, and Corporate Investment : Evidence from Panel Data. The Journal of Finance, 47(4), 1425-1460.

Zingales, L. (2000). In Search of New Foundations. The Journal of Finance, 55(4), 16231654. 